\title{
STUDY OF HEALTH PROBLEMS AND NUTRITIONAL STATUS OF TEA GARDEN POPULATION OF ASSAM
}

\author{
G. K. MEDHI, N. C. HAZARIKA, B. SHAH*, J. MAHANTA
}

\section{ABSTRACT}

BACKGROUND: Assam is the highest tea producer state in the country. There is scarcity of reliable information on health and nutritional status among tea garden population of Assam to enable initiating public health response to their health needs. AIMS: To describe health problems and nutritional status among tea garden population of Assam. SETTINGS AND DESIGN: Community-based cross-sectional survey in eight randomly selected tea gardens of Dibrugarh district of Assam. MATERIALS AND METHODS: Socio-demographic and behavioral characteristics of participants were recorded. Health problems and nutritional status were assessed through medical examination, evaluation of medical records, anthropometry and laboratory investigations. STATISTICAL ANALYSIS: Percentage prevalence; Chi-square test was applied wherever applicable. RESULTS: Out of 4,016 participants, 1,863 were male and 2,153 were female. They were mostly illiterate, and nearly $52.9 \%(1,197$ of 2,264) of adults were manual workers in the garden. Alcohol and oral tobacco use were common. Prevalence of underweight among children was 59.9\% (357 of 596), and thinness among adults was $69.9 \%$ (1,213 of 1,735). Anemia was widespread. Worm infection (65.4\%, 217 of 332); skin problems; respiratory infections, including tuberculosis; filariasis were present in a significant way. Children suffered more in various diseases. Major noncommunicable diseases like hypertension, stroke were emerging in the community and were associated with modifiable risk factors like alcohol and tobacco use. CONCLUSION: Health status of the population can be ameliorated through better hygienic practices, environmental sanitation, creating health awareness, nutritional intervention and overall improvement of socioeconomic conditions of the population.

Keywords: Health problems, noncommunicable diseases, tea garden population, undernutrition

\section{INTRODUCTION}

Reliable information on health problems of a population is an essential pre-requisite for formulating health care system to address

Regional Medical Research Centre, N. E. Region (ICMR), Dibrugarh, Assam, India, *Division of NonCommunicable Diseases, Indian Council of Medical Research (ICMR), New Delhi, India health needs. India is experiencing a health transition, which is posing a great challenge to its health system due to the changing health needs of the population. With the health transition, communicable and

Correspondance:

Dr. J, Mahanta

Regional Medical Research Centre, NE Region, Indian Council of Medical Research, Post Box-105, New Delhi, India. E-mail: icmrrcdi@hub.nic.in 
deficiency diseases are gradually receding while non-communicable diseases (NCD) are escalating in India. Various sociodemographic factors, nutritional improvement, improvement in health infrastructures including eradication, elimination and control of major communicable diseases are mainly contributing to this changing disease pattern in India. However, among the poor socioeconomic groups, the pace of epidemiological transition is slow, where communicable diseases and undernutrition are still the major causes of disease burden. ${ }^{[1-3]}$ India is vast country and variation occurs in the disease pattern due to the socio-economic gradient and other factors. There is scarcity of health information in many sub-populations in India, which needs to be explored for public health policy needs.

Tea is an important agro-industry of Assam, which contributes immensely to the state's economy. Tea garden population constitutes approximately $1 / 5^{\text {th }}$ of state's population. Poor socio-economic conditions, ignorance due to illiteracy, over-crowded and unhygienic living conditions in the residential colonies make tea garden population vulnerable to various communicable diseases and malnutrition. Scattered reports indicate higher prevalence of undernutrition and infectious conditions like filariasis in this population. ${ }^{[4-8]} A$ recent study showed that NCDs like hypertension is emerging as important public health problem among them, which may be partly due to the excessive use of alcohol and tobacco. ${ }^{[9]}$ There may be some also specific health problems, which may be related to their occupation. The information, available on health problems and nutritional status among them, is not adequate for public health planning. Hence, we conducted a survey to with an objective to identify the health problems and nutritional status of tea garden population of Assam. The findings allow us to discuss their health scenario against the backdrop of their socioeconomic condition and lifestyles, which will have important public health implication.

\section{MATERIALS AND METHODS}

The study was conducted among tea garden population of Dibrugarh district of Assam during the period 2002-2003. Approval of the Institutional Ethical Committee of Regional Medical Research Centre for Northeast India, Indian Council of Medical Research (ICMR) was taken initially to carry out the study.

Dibrugarh is the hub of tea industry and situated in the eastern corner of the state comprising a total land area of $3381 \mathrm{~km}^{2}$. The workers of tea plantation industry migrated to Assam from states like Madhya Pradesh, Bihar, Orissa and Andhra Pradesh in the latter part of nineteenth to early twentieth century. ${ }^{[9]}$ These workers are solely dependent on this industry for their livelihood and generally at least one member of every family is engaged in tea industry mainly as daily waged manual workers. Both adult male and female are equally employed. They work mainly as tea-pluckers, but small proportion of them are also engaged in factory, office etc. Fixed daily wage is paid to them for the working days. However, they are also paid extra amount for generating more than stipulated work-output. They are also paid bonus during festivals. They are mostly illiterate. Most of them reside in the rent-free houses in the residential colonies situated within the tea estates. The over-crowed and unhygienic conditions of colonies make them vulnerable to various diseases. Within the family campus, many families keep domestic animals and birds. Most of garden labourers purchase various household staffs from weekly market held in garden. Food staffs are kept open in the market in unhygienic conditions. There are hospitals and medical officers in each tea garden for providing free medical services to the workers/dependents and implement various health programmes. Food staffs are also provided to the workers family in a subsidized rate.

A multistage sampling design was adopted in the study for the selection of the individuals to make the samples representatives of the population. Eight out of 138 tea gardens of Dibrugarh districts was selected randomly as first stage unit, followed by random selection of 880 households within the primary sampling unit in the second stage to reach out the study individuals. The tea garden list for sampling frame was prepared in consultation with the district assistant labour commissioner office. All the individuals in the selected households irrespective of age and sex were eligible to participate in the study. There are about 3 lakhs tea garden population in the district and total population of the eight sampled gardens were about twenty seven thousands. A total of 4016 individuals (male-1863 and female2153) from 880 selected households participated in the study, achieving a response rate of about $90 \%$. (Numbers of participants: Garden 1-387, Garden 2-440,
Garden 3-905, Garden 4-513, Garden 5-498, Garden 6-407, Garden 7-358 and Garden 8-508) Data was collected by house to house visit. Socio-demographic informations like age, sex, educational status, occupation status, availability of household toilet and behavioural charecteristics like uses of tobacco and alcohol were collected using a pre-designed and pre-tested questionnaire. Informed consent was taken from all the participants and from the parents of minor participants before collection of data.

The clinicians of the study team carried out general physical examinations of the participants specifically looking into respiratory infection, diarrhoea, skin infection, leprosy, filariasis, gastro-intestinal problem and musculoskeletal (back pain) problems. Information on disease symptoms was obtained from individuals using probing techniques. Stroke and epilepsy cases as per definition used in the study were also recorded. ${ }^{[10,11]}$ All the available persona medical records including investigation repor and medication held by the persons were evaluated and were recorded. Based on al the information collected, a diagnosis of health conditions were made by the same clinicians who collected the data fo maintaining the consistency. Health conditions were coded according to alphanumeric coding of $10^{\text {th }}$ revision of international classification of diseases (ICD 10). Some of the conditions were collapsed into one category to make the list less exhaustive. Treatment for leprosy or tuberculosis in the last six months was also recorded. Sitting blood pressure of the adults 
( $\geq 20$ years) was measured according to the standard procedures. Hypertension was defined as $\mathrm{SBP} \geq 140 \mathrm{mmHg}$ and/or $\mathrm{DBP} \geq 90$ $\mathrm{mm} \mathrm{Hg}$ and/or treatment with antihypertensive drugs. ${ }^{[12]}$

Two anthropometric measurements i.e., height and weight were measured using standard procedures. Weight for age below 2SD of reference median was classified as underweight. ${ }^{[13]}$ For adults ( $\geq 20$ years) body mass index (BMI): weight in $\mathrm{kg} /$ height in metres $^{[2]}$ value less than 18.5 was considered as thinness or chronic energy deficiency and BMI more than 25 was considered as overweight.

Stool examinations for helminthic infection (formal-ether concentration technique), blood haemoglobin estimation (cyanmethaem oglobin method) were carried out in sub-samples. World health organization recommended cut-off points of haemoglobin level were used to define anaemia. ${ }^{[14]}$ To detect microfilarae (mf) of Wuchereria brancrofti night blood smear was done as per protocol of the centre in sub-samples. Diseases identified through laboratory investigations were also coded with ICD-10 coding.

\section{Statistical Analysis}

Data analysis was done using EPI 6 software. Prevalence of diseases was estimated in percentage and computed separately for both male and female. Prevalence of certain health conditions like tuberculosis, leprosy was expressed in per thousand of populations. The prevalence of

health problems and nutritional status among different groups were compared and tested for statistical significance by applying Chisquare test wherever applicable. A $P$-value 0.05 or less was considered as statistically significant.

\section{RESULTS}

Of the total 4016 participants, 1863 (46.4\%) were male and $2153(53.6 \%)$ were female [Table 1]. Above the age of six years of age, $65.1 \%$ (2001 of 3075 ) were illiterate. Out of the total adult population ( $\geq 15$ years), $52.9 \%$ (1197 of 2264) were manual workers. Of the total individuals ( $\geq 15$ years), $59.9 \%$ (1356 of 2264) were alcohol and $72.5 \%$ (1641 of 2264) were non-smoked tobacco users. Smoking rate was $7.7 \%$ (174 of 2264). Out of the total, $2530(63 \%)$ individuals had access to a household toilet.

The prevalence of underweight was $59.9 \%$

Table 1: Distribution of subjects by age, sex, education and occupation

\begin{tabular}{llll}
\hline Variables & Malen (\%) & Femalen (\%) & Totaln $(\%)$ \\
\hline
\end{tabular}

Age groups (Years)
$0-14$

$0-14$
$15-44$
$45-59$
$60+$
All age

All age
Educational lev

Illiterate

Primary

Middle

Secondary and
higher

higher
Occupationtt
No occupation

$\begin{array}{llll}\text { No occupation } & 401(38.8) & 624(50.7) & 1025(45.3)\end{array}$ $\begin{array}{lccc}\text { Daily wage labourer } & 597(57.8) & 600(48.7) & 1197(52.9) \\ \text { Higher grades } & 35(3.4) & 7(0.6) & 42(1.9)\end{array}$

TOnly includes individuals aged $\geq 6$ years (Male-1412, Female1662, Total-3075), +†Only includes individuals aged $\geq 15$ years
of age (Male-1033, Female-1231, Total-2264)
(357 of 596) among preschool children [Table 2]. Prevalence of thinness was significantly higher $(P<0.01)$ among female $(73.1 \%, 499$ of 760$)$ than male $(65.7 \%, 713$ of 975$)$. Prevalence of anaemia was $71.8 \%$ (112 of $156)$ and $72.2 \%$ (153 of 212) among male and female respectively $(P>0.05)$. Clinical signs of Vit A, Vit B-complex and Vit C deficiency were observed in $2.2 \%$ (17 of 779 ), 3.2\% (25 of 779 ) and $1.3 \%$ (10 of 779 ) respectively among the children (0-15 years).

The distribution of various morbid conditions [Table 3] indicates that $65.4 \%$ (217 of 332) of individuals harbor at least one intestinal helminthes. Prevalence of $A$. Lumbricoides, T. trichiura and $A$. duodenale/N. americanus (hookworms) infection was $49.4 \%$ (164 of 332 ), $29.8 \%$ (99 of 332 ) and $5.4 \%$ (18 of 332 ) respectively. Mf of Wuchereria brancrofti was detected in $8.7 \%$ (20 of 231) of blood slides. In all, $0.6 \%$ (23 of 4016 ) persons had clinical manifestations of filariasis.

Other common health problems observed in the study were respiratory problems (6.7\%), various skin lesions (scabies-2.9\%, abscess

Table 2: Prevalence of underweight among children, chronic energy deficiency among adults and anaemia ( $\geq 20$ years)

\begin{tabular}{|c|c|c|c|}
\hline $\begin{array}{l}\text { BMI } \\
\text { (Weight in } \mathrm{Kg} / \\
\text { Height in } \\
\text { metre }{ }^{(2)} \text { ) }\end{array}$ & Male & Female & Total \\
\hline 18.5 & $\begin{array}{c}\text { Total male } \\
(\mathrm{N}=760) \\
499(65.7 \%)\end{array}$ & $\begin{array}{c}\text { Total female } \\
(\mathrm{N}=975) \\
713(73.1 \%)\end{array}$ & $\begin{array}{c}\text { Male+female } \\
(\mathrm{N}=1735) \\
1213(69.9 \%)\end{array}$ \\
\hline $\begin{array}{l}\text { Prevalence of u } \\
\text { Underweight } \\
<-2 S D\end{array}$ & $\begin{array}{c}\text { underweight am } \\
\text { Male }(\mathrm{N}=285) \\
169(59.3 \%)\end{array}$ & $\begin{array}{l}\text { ong under } 5 \text { childre } \\
\text { Female }(\mathrm{N}=311) \\
188(60.5 \%)\end{array}$ & $\begin{array}{l}\text { en } \\
\text { Total }(\mathrm{N}=596) \\
357(59.9 \%)\end{array}$ \\
\hline Prevalence of & & $\begin{array}{l}\text { tea garden childre } \\
\text { Female }(n=212)\end{array}$ & \\
\hline naemic & $112(71$ & $153(72.2 \%)$ & $265(72.0$ \\
\hline
\end{tabular}

or furuncle or carbuncle-2.5\% and other skin lesions-2\%). Prevalence of diarrhoea was $1.7 \%(n=70)$. Prevalence of pulmonary tuberculosis was $11.7 / 2000(n=47)$ and prevalence of leprosy was $0.8 /{ }^{\prime} 000(n=3)$ Proportion of children (0-5 years) who was suffering from respiratory problems and diarrhoea at the time of survey was $12.8 \%$ (97 of 761 ) and $3 \%$ (23 of 761 ) respectively. Prevalence of epilepsy was 7.3/'000 ( $n=29)$. Hypertension was diagnosed among $45.9 \%$ (817 of 1782) of adults ( $\geq 20$ years). An increasing trend of hypertension in both sexes with increasing age was also detected [Table 4]. Prevalence of hemiplegia was $43.7^{\prime} 000$ (9 of 206) in the elderly age group ( $\geq 60$ years). Back pain was registered in $8.7 \%$ (130 of 1487 ) of individuals in the age group above 25 years.

We also compared the prevalence of some important health problems according to some important background characteristics of sampled individuals like individual education (or maternal education in case of children below 6 years), availability of a household toilet and use of alcohol and tobacco (results not shown in table). Prevalence of diarrhoea was $1.4 \% \quad(n=29)$ among those who had access to a household toilet for defecation, which was significantly lower $(P<0.001)$ as compared to $2.8 \%(\mathrm{n}=42)$ prevalence among those who didn't have access to a household toilet. Similarly, among those who had access to a household toilet, prevalence of one or more intestinal helminths was 58.8\% (141 o $240)$, which was significantly highe $(P<0.001)$ as compared to $82.6 \%$ (76 of 92$)$ prevalence among those who didn't have a toilet facility in the household. 
Table 3: Morbidity conditions observed in the study subject according to international classification of diseases (ICD-10) coding

\begin{tabular}{|c|c|c|c|c|}
\hline $\begin{array}{l}\text { ICD-10 } \\
\text { code }\end{array}$ & Name of disease & Male (\%) & Female (\%) & Total (\%) \\
\hline A09 & Diarrhoea & $31(1.7)$ & $39(1.8)$ & $70(1.7)$ \\
\hline A15 & Pulmonary tuberculosis & $18(9.7)$ & $29(13.5)$ & $47(11.7)$ \\
\hline A 301 & Leprosy & $2(1.1)$ & $1(0.5)$ & $3(0.8)$ \\
\hline B74 & Filariasis & $18(1.0)$ & $5(0.23)$ & $23(0.6)$ \\
\hline B83* & Intestinal worm infestation & $103(65.6)$ & $114(65.1)$ & $217(65.4)$ \\
\hline B86 & Scabies & $55(3.0)$ & $60(2.8)$ & $115(2.9)$ \\
\hline D $50^{\text {** }}$ & Anaemia & $112(71.8)$ & $153(72.2)$ & $265(72.0)$ \\
\hline E $50^{* \star \star}$ & Vit A deficiency & 7 (2.1) & $9(2.2)$ & $17(2.2)$ \\
\hline E $53^{* \star \star}$ & B-complex & $11(2.9)$ & $14(3.5)$ & $25(3.2)$ \\
\hline E $54^{* * *}$ & Vit C deficiency & $5(1.3)$ & $5(1.2)$ & $10(1.3)$ \\
\hline G40" & Epilepsy & $12(6.5)$ & $17(7.9)$ & $29(7.3)$ \\
\hline G81 & Hemiplegia and paralysis & $10(0.5)$ & $6(0.3)$ & $16(0.4)$ \\
\hline $\mathrm{H} 25^{\S}$ & Senile cataract & $24(25.3)$ & $28(26.2)$ & $52(25.3)$ \\
\hline $110^{\ddagger}$ & Hypertension & $389(49.1)$ & $428(43.3)$ & $817(45.9)$ \\
\hline J00-02, J06, J20, J40, & Respiratory problems & $129(6.9)$ & $141(6.5)$ & $270(6.7)$ \\
\hline K29 & Gastritis & $32(1.7)$ & $72(3.3)$ & $104(2.6)$ \\
\hline L02 & Cutenous abscess, furuncle and carbuncle & $51(2.7)$ & $48(2.2)$ & $99(2.5)$ \\
\hline L30 & Other dermatitis & $43(2.3)$ & $37(1.7)$ & $80(2.0)$ \\
\hline M13 & Joint pain/arthritis & $7(0.4)$ & $14(0.7)$ & $21(0.5)$ \\
\hline M54" & Musculo-skeletal pain (Dorsalgia) & $55(7.5)$ & $75(9.9)$ & $130(8.7)$ \\
\hline R10 & Pain abdomen & $43(2.3)$ & $58(2.7)$ & $101(2.5)$ \\
\hline
\end{tabular}

"Figure in parenthesis is in per thousand populations, ${ }^{*}$ The total numbers of subjects screened for those conditions are 332 (Male157, Female-175), ,**The total numbers of subjects screened for that condition is 368 (Male-156, Female-212), ${ }^{* * *}$ The total numbers of subjects screened for those conditions are 779 (Male-374, Female-405), Sonly geriatric age group is included (Male-99, Female-
107 . Total-206), *The total numbers of subjects screened for those conditions are 1782 (Male-793, Female-989), "Only individuals 107, Total-206), 看e total numbers of subjects screened for those con
more than 25 years were included (Male-733, Female-754, Total-1487)

Table 4: Prevalence of hypertension among adults ( $\geq 20$ years) according to the defined criteria - SBP $\geq 140$ or DBP $\geq 89$ (JNC VI classification)

\begin{tabular}{l|l}
\hline Age group (years) & Hypertensive N (\%) \\
\hline $20-29(\mathrm{n}=582)$ & $132(22.7)$ \\
$30-39(\mathrm{n}=477)$ & $201(42.1)$ \\
$40-49(\mathrm{n}=350)$ & $201(57.4)$ \\
$50-59(\mathrm{n}=170)$ & $115(67.7)$ \\
$59+(\mathrm{n}=203)$ & $168(82.8)$ \\
Total $(\mathrm{N}=1782)$ & $817(45.9)$ \\
&
\end{tabular}

An educational gradient in the prevalence of most of the health problems and undernutrition was also observed. Out of 44 pulmonary tuberculosis cases (age $>6$ years), only 2 (4.9/'000, 2 of 406) were among those who were educated beyond primary school as compared to 42 cases (15.7/'000, 42 of 2669) among those who were illiterate or educated up to the primary level $(P>0.05)$.
The prevalence of thinness was $73.3 \%$ (969 of 1322 ) among illiterate which came down to $65 \%(139 / 214)$ among those with primary level education and $52.8 \%$ (105 of 199) among those with educational level beyond primary school in a statistically significant way $(P<0.001)$. Similarly, in case of children, more children (61.4\%, 302 of 492$)$ were found to be underweight among those whose mother were illiterates than those children (51.4\%, 55 of 107) whose mother had formal schooling $(P<0.05)$.

Prevalence of hypertension among alcohol users was $49.1 \%$ (525 of 1070), which was significantly higher $(P<0.001)$ as compared to $41 \%$ (292 of 712 ) among non-users. Similarly, prevalence of hypertension among tobacco users was $49.1 \%$ (692 of 1408) as compared to $33.4 \%$ (125 of 374 ) among non-users, which was statistically significant $(P<0.001)$.

\section{DISCUSSION}

The survey revealed high magnitude of undernutrition and infectious diseases among tea garden population of Assam. Nutritional problems like underweight among children $(59.9 \%)$, thinness among adults $(69.8 \%)$ and micronutrient deficiency disorders like anaemia $(72 \%)$ were widespread. Common infectious diseases were worm infestation $(65.4 \%)$, respiratory problems $(6.7 \%)$, diarrhoea $(1.7 \%)$, skin infections, filariasis $(0.6 \%)$ and pulmonary tuberculosis (11.7) '000). The study also registered a significant burden of NCDs like hypertension (45.9\%), senile cataract $(25.3 \%)$, epilepsy $(7.3 / 000)$, back-pain $(8.7 \%)$.

Higher prevalence of underweight was observed among children in comparison to the prevalence in general, but comparable to children belonging to poor socio-economic groups. ${ }^{[15,16]}$ Similarly, as reported earlier, this study also found higher prevalence of thinness among adults compared to other reports in India. ${ }^{[7,17]}$ Prevalence of Vit A, Bcomplex deficiency disorders among children was comparable to lower socio-economic groups. ${ }^{[16,18]}$ Extent of anaemia was found to be higher in comparison to other states of India, but comparable to Assam. ${ }^{[15]}$

Of the infectious diseases, prevalence of tuberculosis was higher in comparison to overall prevalence of Assam and India. ${ }^{[19,20]}$ Prevalence of respiratory infection was lower than workers engaged in dust producing textile industry. ${ }^{[18]}$ However, prevalence among children was comparable to triba children. ${ }^{[16]}$ Prevalence of worm infestation was higher as compared to relatively bette off population of adjacent rural area. ${ }^{[21]} \mathrm{A}$ higher microfilaria rate in tea labourers was observed compared to indigenous population. ${ }^{[6]}$

Most of these diseases among them appeared to be emanated from poor personal and household hygiene, unsatisfactory sanitation and housing coupled with ignorance due to lack of education. Poo nutrition among them also probably makes them vulnerable to infectious diseases and vice versa. Presence of household toilet was found to reduce orofecally-transmitted diseases, as also reported earlier. ${ }^{[8]}$ However high prevalence even among toilet holders may be because of contaminations of surroundings due to open field defecation by large numbers of other community members and poor maintenance of toilets facilities. Unfavorable housing may be attributable to higher rate of tuberculosis and respiratory conditions. Similarly, use of biomass cooking fuel may also contribute to respiratory diseases. ${ }^{[22]}$ Vector borne disease like filariasis is endemic among tea labourers due to abundance of disease vectors, availability of $m f$ carriers acting as reservoir and abundant mosquito breeding places in peridomestic surroundings due to presence of stagnant water bodies. ${ }^{[4,5]}$

We observed positive impact of individuals education on health and nutrition. Similarly, impact of maternal education on child health 
and nutrition was also observed. Lack of education probably adversely influences in health awareness and health-seeking behaviours contributing to higher disease rate. ${ }^{[5]}$ Parental occupation seems also impinges on child health and nutrition as they remain busy in tea gardens neglecting timely feeding of children or taking sick children to hospital. Exclusive breast-feeding is a positive health practice among them, but adverse cultural practices like delay in weaning is an important factor of undernutrition among infants. ${ }^{[23]}$

Adequate dietary supply is required to the workers engaged in occupation, which demands continuous physical labour. However, it is surprising to see a higher rate of undernutrition among them despite supply of subsidized food. In a community where woman is the most important bread earner for the family, high prevalence of thinness and anaemia may have adverse impact on family income as in tea garden wage is directly related to work output. Adverse impact of anaemia and thinness like poor reproductive outcome was also reported from tea garden. ${ }^{[24]}$

epilepsy was comparable to earlier report in India. ${ }^{25]}$ Geriatrics population faced an increased burden of chronic and noncommunicable diseases like hypertension, paralysis and senile cataract. Back pain was complained by a significant numbers of adults, which was lower compared to workers who require lifting or heavy work, but comparable to others. ${ }^{[18,26]}$ Most of the tea garden workers were mainly involved with non-mechanized manual works in this study. Hence, work places related injuries were not observed.

The present study, being a cross-sectional one, has inherent limitations of crosssectional study and can't depict the true picture of diseases in the community. Variation in the diseases may occur due to the locations of the garden and other factors. Seasonal variation was also not taken into account. There is also possibility of underestimation of diseases because of inability of illiterate labourers to express their problems. We also didn't gather data on gynecological diseases, vaccine preventable diseases and many neuro-psychiatric conditions and only limited laboratory investigations were conducted. One of the important strength of the study was that the data was gathered through a populationbased survey by clinicians did the assessment of health problems, which gives more reliability of information than selfreported information or lay reporting.

\section{CONCLUSION}

Despite some limitation, the study identified broad dimension of health and nutritional problems of tea garden population of Assam, based on which public health action can be strengthened. A comprehensive public health policy should be developed including preventive, promotive and curative measures to address the health and nutritional needs of tea garden population. Specific strategy should be developed for improving nutrition. Welfare measures by garden authorities should be strengthened for better sanitary measures and safe drinking water, better housing, adequate food supply, medical care and for overall improvement of socioeconomic condition. Equally important is to educate the community about personal hygienic practices and environmental sanitation, taking preventing measures against commonly prevalent diseases, health risk associated with alcohol and tobacco, appropriate child-rearing practices etc. Although, in every gardens hospital and medical officers are available, many of the curable health problems were found to be laying in untreated conditions, because of individuals not availing the services in appropriate time. Response to the various health programmes like de-worming and $\mathrm{HCH}$ care is not satisfactory. Health programmes can be made accessible to community in efficient way through community participation. Already, in some tea gardens, "mothers' club" is formed for community health awareness and doing well and should be extended to all the gardens. Periodic health check up is also advisable to monitor health and nutrition. Further research should be carried out to understand more precisely the factors contributing the various diseases in this community, which will help in undertaking interventional measures to ameliorate their health status. The study also emphases the need for more research on health problems more specifically linked their occupation.

\section{ACKNOWLEDGMENT}

The authors are grateful to Indian Council of Medical Research (ICMR), New Delhi, India, for supporting the study through an extra-mural funding.

\section{REFERENCES}

1. World Health Organization. The World Health Report, Making Difference. WHO: Geneva; 1999.

2. Ramana GN, Sastry JG, Peters D. Health transition in India: Issues and challenges. Natl Med J India 2002;15:37-42.

3. Srinath Reddy K, Shah B, Varghese C, Ramadoss A. Responding to the threat of chronic diseases in India. Lancet 2005;366:1744-9.

4. Dutta $\mathrm{P}$, Gogoi BK, Chelleng PK, Bhattacharyy DR, Khan SA, Goswami BK, et al. Filariasis in the labour population of a tea estate in Upper Assam. Indian J Med Res 1995;101:245-6.

5. Khan AM, Dutta P, Khan SA, Mahanta J. A focus of lymphatic filariasis in a tea garden workers community of central Assam. J Environ Bio 2004;25:437-40.

6. Mahanta $B$, Handique $R$, Narain K, Dutta $P$, Mahanta J. Transmission of bancroftian filariasis in tea agro-ecosystem of Assam, India. Southeast Asian J Trop Med Public Health 2001;32:581-4.

7. Biswas D, Hazarika NC, Doloi P, Mahanta J. Study on nutritional status of tea garden workers of Assam with special emphasis on body mass index (BMI) and central obesity. J Hum Ecol 2002;13:299302.

8. Traub RJ, Robertson ID, Irwin P, Mencke N Andrew Thompson RC. The prevalence, intensities and risk factors associated with geohelminth infection in tea-growing communities of Assam India. Trop Med Int Health 2004;9:688-701. 
9. Hazarika NC, Biswas D, Narain K, Kalita HC, Mahanta J. Hypertension and its risk factors in tea garden workers of Assam. Natl Med J India 2002;15:63-8.

10. Aho K, Harmsen P, Hatano S, Marquardsen J, Smirnov VE, Strasser T. Cerebrovascular disease in the community: Results of a WHO collaborative study. Bull World Health Organ 1980;58:113-30.

11. Ellenberg JH, Nelson KB. Sample selection and the natural history of disease. Studies of febrile seizures. JAMA 1980;243:1337-40.

12. The sixth report of the Joint National Committee on prevention, detection, evaluation, and treatment of high blood pressure. 1997;157:2413-46.

13. World Health Organization. Physical status: The use and interpretation of anthropometry. Technical report Series-854. WHO: Geneva; 1995.

14. World Health Organization. Nutritional anemia: Report of a WHO scientific group. Technical Report Series-405. WHO: Geneva; 1968.

15. National Family Health Survey (NFHS-2) 19981999. India. IIPS: Mumbai; 2000.

16. Rao VG, Yadav R, Dolla CK, Kumar S, Bhondeley MK, Ukey M. Undernutrition and childhood morbidities among tribal preschool children. Indian J Med Res 2005;122:43-7.

17. Vijayaraghavan K, Rao DH. Diet and nutrition situation in rural India. Indian $\mathrm{J}$ Med Res 1998;108:243-53.

18. Singh MB, Fotedar R, Lakshminarayana J. Occupational morbidities and their association with nutrition and environmental factors among textile workers of desert areas of Rajasthan, India. J Occup Health 2005;47:371-7.

19. International Institute for Population Sciences. National family health survey ( $\mathrm{MCH}$ and family planning), 1992-1993. Inter-national Institute of Population Sciences: Mumbai, India; 1995

20. Chakraborty AK. Epidemiology of tuberculosis: Current status in India. Indian $\mathrm{J}$ Med Res 2004;120:248-76.

21. Mahanta J, Narain K, Srivastava VK. Intestinal parasitic infection in a rural population of Upper Assam. J Parasitic Dis 1996;20:57-8.

22. Mishra V. Effect of indoor air pollution from biomass combustion on prevalence of asthma in the elderly. Environ Health Perspect 2003;111:71-8.

23. Medhi GK, Mahanta J. Breastfeeding, weaning practices and nutritional status of infants of tea garden workers of Assam. Indian Pediatr 2004;41:1277-9.

24. Phukan RK, Mahanta J. A study of neonatal deaths in the tea gardens of Dibrugarh district of upper Assam. J Indian Med Assoc 1998;96:333-4, 337.

25. Sridharan R, Murthy BN. Prevalence and pattern of epilepsy in India. Epilepsia 1999;40:631-6.

26. Joshi TK, Menon KK, Kishore J. Musculoskeletal disorders in industrial workers of Delhi. Int J Occup Environ Health 2001;7:217-21.

\footnotetext{
Source of Support: ICMR, New Delhi. Conflict of Interest: None declared.
} 